\title{
Study of Solving the Bottleneck Problem of the Estimation of Biological Dose in the Window of Time of Medical Emergency in Large-scale Nuclear Radiation Accidents
}

Gang Liu (D Igscfll@163.com)

Gansu Provincial Center for Disease Control and Prevention

Original research

Keywords: Dose rate, Dicentric chromosome, Biological dosimetry

Posted Date: December 4th, 2020

DOI: https://doi.org/10.21203/rs.3.rs-120520/v1

License: (c) (i) This work is licensed under a Creative Commons Attribution 4.0 International License. Read Full License 


\section{Abstract \\ Purpose}

In order to achieve the goal of rapid response, effective disposal and protection of life of large-scale radiation events, how to establish the uniform standard curve of biological dose estimation for chromosome aberration analysis becomes an urgent need.

\section{Methods}

Chromosomal aberrations with different irradiation dose rates were used to analyze the biological dose curve and the share of the "dicentric + ring" caused by the dose rate at each dose point. The dose-rate effect of ${ }^{60}$ Co-rays on peripheral blood lymphocytes was analyzed by statistical method .

\section{Results}

Irradiation dose is dominant ; At each dose point, "(dicentric chromosome + centric rings) /cell" is proportional to "dose rate", that is, $Y$ $=k X+b ;$; Between 1-5Gy dose, "(dicentric chromosome + centric rings) /Cell " holds a quadratic linear relationship with dose rate, that is, $y=a x^{2}+b x+c$.

\section{Conclusion}

The fraction of "dicentric + ring" caused by dose rate was calculated, if "Dose rate" is Z Gy• $\min ^{-1}$, it corresponds to an increase in linear relationships. Biological dose estimation curve $: Y=3.318 \times 10^{-3}+2.0541 \times 10^{-2} \mathrm{x}+7.1721 \times 10^{-2} \mathrm{x}^{2}\left(1.16 \mathrm{~Gy} \cdot \mathrm{min}^{-1} \square \mathrm{R}^{2}=0.9997\right)$ (3). Dose rate $: Y$ Dose rate $=1.2534 \times 10^{-2} \mathrm{x}^{2}+6.6164 \times 10^{-2} \mathrm{x}-2.732 \times 10^{-3} \llbracket 0.01 \mathrm{~Gy} \cdot \mathrm{min}^{-1} \square \mathrm{R}^{2}=0.999 \mathrm{Q}(1)$. The estimated dose is formula (3) $-(1.16-Z) \times$ formula (1).

\section{Introduction}

In response to the problem of rapid and high-throughput accurate estimation of personal high biological dose exposure during nuclear emergencies and nuclear terrorism, we will focus on research to solve the bottleneck of large quantities of biological dose estimation problem in large-scale radiation medical emergency events within a window period quickly and dose estimation of the illuminated staff clearly to determine whether the staff are irradiated the radiation damage degree and the important basis of classification of early treatment measures to prevent the public panic, and the reasonable medical treatment. the chromosome "dicentric + ring"with the irradiation dose rate on the rise of share are calculated, Research and development of a unified medical emergency curve for nuclear and radiation accidents are carried forward based on human peripheral blood lymphocyte chromosome "dicentric + ring" analysis. Rapid response to large-scale radiation events is developed to achieve the goal of rapid response, effective disposal and protection of life.

The classification of potential victims in medical rescue of nuclear and radiation accidents will help to make better use of current medical resources and improve the efficiency of rescue.Biodosimetry (BIOdosimetry) is an effective method to evaluate the extent of external radiation damage.The application of biological dose estimation method in nuclear accident classification is of great significance for effective medical rescue in nuclear accidents.

For a long time, dose assessment after ionizing radiation (IR) exposure has been done by analyzing chromosomal aberrations in mitotic cells. Analysis of metaphase dicentric chromosomes in peripheral blood lymphocytes has allowed the development of biodosimetry and has become the preferred method for suspected IR overexposure (International Atomic Energy Agency (IAEA) 2011).Cytogenetic dosimetry: Applications in radiation emergency preparedness and response. ${ }^{[1]}$

Each institution was required to establish a biological dose estimation curve for chromosome aberration analysis. Under these circumstances, we cannot form a joint response to a nuclear and radiological accident. 


\section{Materials And Methods}

Reagents: Biochemical RPMI-1640 (Xi'an, China), Methanol and glacial acetic acid were obtained from Spectrochem (China). Giemsa stain was purchased from Sigma-Aldrich (St Louis, Missouri), fetal bovine serum (FBS), potassium chloride and PI were obtained from Sigma Chemicals (Shanghai). Phytohemagglutinin-M were purchased from Invitrogen (GIBCO, Beijing).

Instruments: The SANYO MCO-20AIC $\mathrm{CO}_{2}$ incubator from SANY (Sakata, Japan); microscope from OLYMPUS (OLYMPUS CK20, Tokyo, Japan).Quick CRP analyzer (Shanghai, China).

\section{Collection, irradiation, and transportation of blood}

All donors give informed consent. No recent ionizing radiation exposure, no smoking. For each exercise, blood samples were drawn from each of 5-6 donors (ages 26-68 years), Blood was collected through vein and added into $20 \mathrm{ml}$ of lithium heparinization tube by puncture. All blood samples were irradiated in vitro in a test tube at room temperature.

Irradiation at 8 different dose points between 0.0 and 5.0Gy. Peripheral blood of volunteers was collected about $20 \mathrm{~mL}$ and divided into 1-ml portions. At $37 \pm 1{ }^{\circ} \mathrm{C}$, each vial was exposed to different doses of ${ }^{60} \mathrm{Co}$ radiation ( 2.8 and $3.7 \mathrm{~Gy}$ ). One vial was not irradiated and kept as a control.

\section{Cell culture and harvest}

Based on general guidelines provided by the International Atomic Energy Agency (IAEA 2001, 2011) and ISO 19238 and 21243 (ISO 2004, 2008).

\section{Dicentric chromosome assay}

Cells were incubated at $37^{\circ} \mathrm{C}$ and $5 \% \mathrm{CO}_{2}$ for $50 \mathrm{~h}$, and only the first metaphase diffusion was used to count the dichotomies. The standard way to ensure that only the first metaphase diffusion is scored is to add colchicine in advance. The whole blood culture method was adopted, and the ratio of blood to medium was $1: 10.0 .5 \mathrm{~mL}$ heparin lithium was added to $5 \mathrm{~mL}$ lymphocyte culture medium as anticoagulant. Prepare cell suspension. Cells were treated with $5 \mathrm{~mL} \mathrm{KCl}$ hypotonic twice every 30 minutes, and then fixed with Carnoy solution for 4 times for 5 minutes each time. Prepare and stain for Giemsa, air dry and code. Used for chromosome aberration analysis of lymphocytes. ${ }^{[1]}$

Sufficient mitotic phase is analyzed according to the following formula, where $\mathrm{p}$ is the ratio of "dicentric+ ring" aberrations cells, $\mathrm{n}$ is the number of cells to be analyzed, and $p$ can be calculated after a certain number of aberrations cells are obtained by counting analysis. At least 100 "dicentric+ ring" or 1000 mitotic phases were analyzed for each sample and biological dose estimates were made.

$n=(1-p) \times 96.04 / p$

For example, for an accident exposed person, 100 metaphase mitotic cells were observed and 18 aberrant cells with double centromere and ring were found. When an error of $20 \%$ is allowed, calculate the number of cells to analyze.

Formula:

$N=[(1-0.18) \llbracket 96.04] / 0.18=438$

\section{Cytokinesis block micronucleus assay}

Two hours after exposure, $9 \mathrm{ml}$ medium (80\% RPMI-1640 and 20\% FBS) was added to $1 \mathrm{ml}$ of blood. $\mathrm{Ph}-\mathrm{M}(20 \mathrm{mg} / \mathrm{mL})$ was stimulated and incubated at $37^{\circ} \mathrm{C} .{ }^{[2,3]}$

At the 44th hour, cyto-b was added $6 \mathrm{mg} / \mathrm{mL}$ and cultured for $28 \mathrm{~h}$.After incubation for 72 hours, cells were collected with a pre-cooled hypotonic solution (0.075M) and fixed with Carnoy's solution (methanol/acetic acid 5:1).For each dose of irradiated blood sample, multiple sections were cast, air-dried, and coded. 
Then $8 \%$ Giemsa solution was dyed in phosphate buffer $(\mathrm{pH} 6.8)$ and $\mathrm{PI}(1 \mathrm{~mol} / \mathrm{mL})$, and scored blindly manually, and MetaSystems automatically scored. ${ }^{[2,3]}$

\section{Results}

Each Dose Point in the Fitted "Dose-Effect Curve by DIC Analysis. (See table 1)

Abbreviation: DIC, dicentric chromosome.

In the following dose ranges, the obtained data were fitted by the method of minimum sum of squares according to the four mathematical models provided by WHO, the significance test of the regression coefficient was carried out, and the correlation index $\left(R_{2}\right)$ test of the fitting degree of the equation was carried out. According to the regression coefficient significance test $(P)$, the degree of fit $\left(R_{2}\right)$, the difference between a value and the spontaneous aberration rate, the optimal regression equation was selected for each dose range. $\varangle 0-0.5 \mathrm{~Gy}(\mathrm{Dic}+\mathrm{r}) \otimes \mathrm{Y}=3.99 \mathrm{D}^{1.1033} ; 0-0.5 \mathrm{~Gy}$ (The total distortion), $\mathrm{Y}=6.5328 \mathrm{D}^{1.0196} \llbracket 0.5-5.0 \mathrm{~Gy}(\mathrm{Dic}+\mathrm{r}), \mathrm{Y}=7.1466 \mathrm{D}^{1.8933} ; 0$ $5.0 \mathrm{~Gy}(\mathrm{Dic}+\mathrm{r}), \mathrm{Y}=8.9846 \mathrm{D}^{1.632} \cdot 0-6.0 \mathrm{~Gy}(\mathrm{Dic}+\mathrm{r}), \mathrm{Y}=9.23 \mathrm{D}^{1.6606}$.

$Y=5.32 \times 10^{-2} \mathrm{D}+4.43 \times 10^{-2} \mathrm{D}^{2} \otimes 0.27 \mathrm{~Gy} \cdot \mathrm{min}^{-1} \otimes \mathrm{R}^{2}=0.9999 \rrbracket$

Biological dose estimation and error analysis were performed on the national assessment samples in 2015 and 2016 by using the dose curves established by different dose rates in different laboratories.

The dose curves with different exposure dose rates established by different laboratories were used to estimate the biological dose of the national assessment samples in 2015 and 2016. The error analysis is shown in table 2ه3.

Table 3 shows that the absolute value of the error increases with the increase of the radiation dose rate, which is significant with the increase of the radiation dose. It indicates that the irradiation dose is dominant and the irradiation dose rate is secondary.

Analysis of double + ring (\%) and irradiation dose results of chromosome aberrations in peripheral blood irradiated by different dose rates in different laboratories (see table 4)

Table4 shows that the original data of the biological dose estimation curve of chromosome aberration established by different laboratories have certain differences when comparing the dose-effect curve of each laboratory. Although there was an increasing trend of different dose rates at the same dose, there were also cases in which the high dose rate irradiation of "dicentric+ring" (\%) of chromosome aberration was lower than that of low dose rate irradiation.

1Gy: $Y=5.936+5.074 x, p=0.018$

2Gy: $Y=19.666+15.354 x, p=0.024$

3Gy: $Y=40.604+29.299 x, p=0.010$

4Gy: $Y=74.908+42.752 x, p=0.012$

5Gy: $Y=122.004+62.054 x, p=0.019$

$\mathrm{Y}$ is the increasing of "dicentric+ring" (\%) cause by the dose rate;

The unit of $x$ is Gy $\mathrm{min}^{-1}$

At each dose point, "Dic $+r /$ Cell" is proportional to "dose rate", that is, $Y=k X+b$, It shown table 5, figure1, 2.

According to the values of $k \rrbracket$

Dose rate $: Y$ Dose rate $=1.2534 \times 10^{-2} x^{2}+6.6164 \times 10^{-2} x-2.732 \times 10^{-3} \otimes 1 \mathrm{~Gy} \cdot \mathrm{min}^{-1} \otimes R^{2}=0.999 \otimes(1)$.

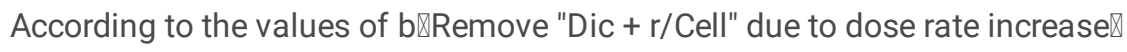


$Y_{\text {Dose } 1}=5.7213 \times 10^{-2} x^{2}+5.5899 \times 10^{-2} \times-6.4592 \times 10^{-3} \bowtie 0.01 G y \cdot \mathrm{min}^{-1} \otimes R^{2}=0.999(2)$.

The dose rate caused by the "dicentric+ring" increase in the share of the analysis, it shown table 6, 7 and Figure 3

The fraction of "dicentric+ring" caused by dose rate was calculated, if "Dose rate" is Z Gy· $\mathrm{min}^{-1}$, it corresponds to an increase in linear relationships.

Biological dose estimation curve $: Y=3.318 \times 10^{-3}+2.0541 \times 10^{-2} \mathrm{X}+7.1721 \times 10^{-2} \mathrm{x}^{2} \rrbracket 1.16 \mathrm{~Gy} \cdot \mathrm{min}^{-1} \rrbracket \mathrm{R}^{2}=0.9997 \rrbracket(3)$.

Dose rate $: Y_{\text {Dose rate }}=1.2534 \times 10^{-2} \mathrm{x}^{2}+6.6164 \times 10^{-2} \times-2.732 \times 10^{-3} \varangle 0.01 \mathrm{~Gy} \cdot \mathrm{min}^{-1} \otimes \mathrm{R}^{2}=0.999 \otimes(1)$.

The estimated dose is formula (3) - (1.16-Z) xformula (1).

\section{Discussion}

Biodosimetry has been used for many years to estimate the amount of ionizing radiation an individual receives. This information is of vital importance to the medical community as it helps to develop effective and timely treatment plans for potential patients.

Several biomarkers have been developed to measure radiation damage. Traditionally, dicentric chromosome testing (DCA) is a dose estimation method based on the frequency of dicentric chromosomes in peripheral blood lymphocytes. As the background dual center frequency is low and stable (0.5\& NDASH; DCA is very sensitive (IAEA 2011) and is particularly sensitive to ionizing radiation damage. In this experiment, when the dose level was as low as 0.1\&Ndash. 0.2Gy, 500\& NDASH; 1000 intermediate extensions were analyzed, but this required many hours of analysis.

Peripheral blood lymphocytes are usually G0 at rest and must be stimulated to enter metaphase. During this process, cells must overcome the different cell cycle checkpoints that control proper progression. When a cell suffers DNA damage, DNA repair mechanisms are activated by other signaling pathways, inducing delays in cellular processes, and triggering programmed cell death when necessary. At checkpoints, $\mathrm{G}_{2} / \mathrm{M}$ ensures that cells do not enter mitosis before they have a chance to repair damaged DNA (Jeggo and Lobrich 2006Jeggo PA, Lobrich M. 2006).The role of DNA repair and cell cycle checkpoint blocking in maintaining genomic stability. DNA repair.Now,92 - 1198.

However, in mass casualty incidents, only patients treated with 2.0 Gy or more did not need such sensitivity.

In these cases, the sensitivity of the analysis can be reduced by reducing the number of metaphase cells, greatly reducing the time required for analysis. Standard shunt DCA analysis only analyzes 50 mid-term diffusions now, providing a detection threshold of $1 / 2$ Gy. Still sufficient to guide the treatment of acute radiation syndrome (ARS) (Lloyd 1997, Lloyd et al. 2000, Voisin et al. 2001, ISO [ISO] 2008;GB/T 28236-2011)

By introducing a scoring technique called \&Lsquo, the time efficiency of sorting based scoring can be greatly improved without losing the accuracy of dose estimation. DCA quick scan;(Flegal et al., 2010,2012).This approach is not based on counting individual centromeres, but checking for obvious damage of intermediate diffusion simply and quickly, thereby eliminating the count of individual chromosomes as traditional DCA (CDCA) methods do to ensure the integrity of the cell which is analyzed, This approach has been shown to be as accurate as traditional triage scoring, while reducing grading time by approximately 6 times (Flegal et al., 2012). ${ }^{[5]}$

Another strategy to improve biodosimetric throughput is the development of a network of biodosimetric laboratories. A number of networks have been established to improve dose estimation throughput, such as the National Biological Dose Response Program (NBDRP) in Canada (Miller et al. 2007), the Biological dosimetry Network in Latin America (Garcia et al. 1995) and the Chromosome network in Japan (Yoshida et al. 2007).In addition, the European Network, the European Biodosimetry Network (RENEB), is being gradually established (Kulka et al. 2012). When a network is established, regular comparisons must be made between the various laboratories of the network to maintain and evaluate accuracy and throughput. Many one-off cross-comparisons have been carried out over the past few years, with each country having a different design within two laboratory networks (Garcia et al. 1995) and between laboratories in different networks or between countries (Roy et al. 2004, Wilkins et al. 2008,Di et al. 2011,Beinke et al. 2013). The purpose of this paper is to describe the comparative results of Canada's National Biological dose Response Program (NBDRP) over the past 6 years. Experiments of similar design are conducted annually, including DCA, routine and rapid scanning, and

Page 5/12 
CBMN analysis. These efforts involve four Canadian reference laboratories and, occasionally, two biodosimetry laboratories in the United States. The lessons learned from these comparisons will be discussed and the importance of repeating the comparison exercise will be emphasized. ${ }^{[6-11]}$

In order to accurately estimate the human biological dose at different dose rates, low, medium and high dose rates were irradiated to human peripheral blood to prepare chromosome samples, and the dose response curves were established according to the doublecenter frequency and loop frequency. The results show that at the same dose level, the distortion frequency increases with the increase of dose rate, and there is an obvious dose rate effect. The estimated absorbed dose of low dose - reaction curve is significantly higher than that of high dose - reaction curve. Therefore, the influence of dose rate should be considered in dose estimation, and the approximate dose rate and dose response curve should be selected to make the estimation results credible.

Using biological dose estimation curve: " $Y=3.318 \times 10^{-3}+2.0541 \times 10^{-2} x+7.1721 \times 10^{-2} x^{2}\left(1.16 \mathrm{~Gy} \cdot \mathrm{min}^{-1} ; R^{2}=0.9997\right)(3) ;$ Dose rate $: Y$ Dose rate $=1.2534 \times 10^{-2} x^{2}+6.6164 \times 10^{-2} \times-2.732 \times 10^{-3} \llbracket 0.01 G y \cdot \min ^{-1} \otimes R^{2}=0.999 \otimes(1)$.

\section{Conclusion}

Establish a unity standard curve of biological dose estimation for the analysis of chromosome aberration.

The fraction of "dicentric + ring" caused by dose rate was calculated, if "Dose rate" is Z Gy· $\mathrm{min}^{-1}$, it corresponds to an increase in linear relationships.

Biological dose estimation curve $: Y=3.318 \times 10^{-3}+2.0541 \times 10^{-2} \mathrm{X}+7.1721 \times 10^{-2} \mathrm{x}^{2}\left(1.16 \mathrm{~Gy} \cdot \mathrm{min}^{-1} ; \mathrm{R}^{2}=0.9997\right)(3)$.

Dose rate $: Y$ Dose rate $=1.2534 \times 10^{-2} \mathrm{x}^{2}+6.6164 \times 10^{-2} \mathrm{x}-2.732 \times 10^{-3}\left(0.01 \mathrm{~Gy} \cdot \mathrm{min}^{-1} ; \mathrm{R}^{2}=0.999\right)(1)$.

The estimated dose is formula (3) $-(1.16-Z) \times$ formula $(1)$.

These findings provide confidence to the medical community. Application of estimated biodosimetry to medical rescue during nuclear and radiation accidents is widespread, the public and government believes that in the event of a nuclear accident, biodosimetry can be applied to manage and medically treat casualties to ensure the minimization of health risks.

On this basis, the chromosome karyotype analysis pretreatment system and chromosome automatic scan analysis system were used to realize the automation of biological dose estimation. Joint laboratories in different parts of the world can respond to nuclear and radiation accidents in a timely manner.

\section{Declarations}

\section{Ethics approval and consent to participate}

The research was approved by the Bioethics Committee at the Gansu provincial center for disease control and prevention. This article does not contain any studies with animals performed by any of the authors.

\section{Consent for publication}

Agreed to publish

\section{Availability of data and materials}

Not applicable

\section{Competing interests}

The authors declare that they have no conflict of interest.

\section{Funding}


This study was funded by the Lanzhou science and technology bureau (2018-1-127) and Gansu provincial health commission (GSWSKY2018-48).

\section{Authors' contributions}

Not applicable

\section{Acknowledgements}

Thanks to Lanzhou science and technology bureau and Gansu Provincial Health Commission for their financial support.

\section{References}

[1] Ruth C. Wilkins Health Canada, Environmental Radiation and Health Sciences Directorate, Ottawa, ON,

CanadaCorrespondenceRuth.Wilkins@hc-sc.gc.ca

, Lindsay A. Beaton-Green Health Canada, Environmental Radiation and Health Sciences Directorate, Ottawa, ON, Canada, Sylvie Lachapelle Health Canada, Environmental Radiation and Health Sciences Directorate, Ottawa, ON, Canada, Barbara C. Kutzner Health Canada, Environmental Radiation and Health Sciences Directorate, Ottawa, ON, Canada, Catherine Ferrarotto Health Canada, Environmental Radiation and Health Sciences Directorate, Ottawa, ON, Canada, Vinita Chauhan Health Canada, Environmental Radiation and Health Sciences Directorate, Ottawa, ON, Canada, Leonora Marro Health Canada, Environmental Radiation and Health Sciences Directorate, Ottawa, ON, Canada, Gordon K. Livingston Oak Ridge Associated Universities, REAC/TS, Radiation Emergency Medicine (REM), Oak Ridge, TN, USA, Hillary Boulay Greene Radiological \&amp; Nuclear Defence and Navigation Warfare, Defence R\&amp;D Canada-Ottawa Research Centre, Ottawa, ON \& Farrah N. Flegal Canadian Nuclear Laboratories Limited, Chalk River, ON, Canada. Evaluation of the annual Canadian biodosimetry network intercomparisons [J]. BIODOSIMETRY COMPARISON, Pages 443451, https://doi.org/10.3109/09553002.2015.1012305

[2] Agrawala PK囚Adhikari JS『Chaudhury NK. Lymphocyte chromosomal aberration assay in radiation biodosimetry[J]. J Pharm Bioallied Sci囚2010囚2(3)凶197-201.

[3] International Atomic Energy Agency. Cytogenetic dosimetry $₫$ Applications in preparedness for and response to radiation emergencies [M].Vienna囚IAEA囚2011.

[4] Ministry of health, PRC, standardization administration of China. Method for estimating biological dose by chromosome aberration GB/T 28236-2011 [S]. Beijing: China standard press, 2012.

[5] GUO Y \ZHANG W『GAO C X『et al. A simple method for human whole blood microcultures and its application in radiation biodosimetry [J]凶Health Phys $₫ 2015 \otimes 109 \llbracket 4 \llbracket \bigotimes 323-326$.

[6] Balakrishnan S『Shirsath K囚Bhat N囚et al. Biodosimetry for high dose accidental exposures by drug induced premature chromosome condensation (PCC) assay[J]. Mutat Res $₫ 2010 \llbracket 699(1 / 2) \llbracket 11-16$.

[7] Pujol M\Puig R囚Caballi 'n MR囚et al. The use of caffeine to assess high dose exposures to ionising radiation by dicentric analysis[J]. Radiat Prot Dosimetry $2012 \bigotimes 149(4) \bigotimes 392-398$.

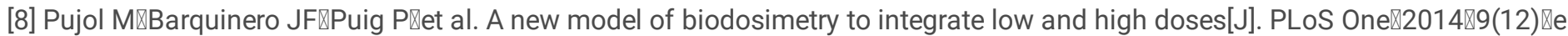
114137.

[9] Fenech M. Cytokinesis-block micronucleus assay evolves into a "cytome" assay of chromosomal instability $₫$ mitotic dysfunction and cell death[J]. Mutat Res $₫ 2006 \varangle 600(1 / 2) \otimes 58-66$.

[10] Song EY『Rizvi SM®Qu CF囚et al. The cytokinesis-block micronucleus assay as a biological dosimeter for targeted alpha therapy[J]. Phys Med Biol囚2008§53(2)『319-328.

[11] Willems P『August L『Slabbert P『et al. Automated micronucleus (MN) scoring for population triage in case of large radiation events[J]. Int J Radiat Biol囚2010囚86(1)囚2-11. 


\section{Tables}

Table 1. The Number of Cells and DICs Analyzed at Each Dose Point in the Fitted "Dose-Effect Curve By DIC Analysis."

\begin{tabular}{|llll|}
\hline Absorbed Dose (Gy) & Cell Number & Dic $+r$ Number & Dic $+r$ /Cell \\
\hline 0.0 & 11000 & 7 & 0.06 \\
\hline 0.25 & 6310 & 60 & 0.951 \\
\hline 0.50 & 6730 & 230 & 3.420 \\
\hline 1 & 769 & 74 & 9.623 \\
\hline 2 & 711 & 211 & 29.677 \\
\hline 3 & 902 & 502 & 55.654 \\
\hline 4 & 793 & 723 & 91.173 \\
\hline 5 & 565 & 780 & 138.05 \\
\hline
\end{tabular}

Abbreviation: Dic, dicentric chromosome; $r$, centric rings

Table 2 Analysis of estimated results of dose curves with different dose rates for national assessment samples

\begin{tabular}{|c|c|c|c|c|c|c|c|c|c|c|c|}
\hline \multirow{2}{*}{\multicolumn{2}{|c|}{$\begin{array}{l}\text { Sample } \\
\text { Number }\end{array}$}} & \multirow{2}{*}{$\begin{array}{l}\text { Cell } \\
\text { Number }\end{array}$} & \multirow{2}{*}{$\begin{array}{l}\text { Dic+ } r \\
\text { Number }\end{array}$} & \multicolumn{2}{|c|}{$0.27 \mathrm{~Gy} / \mathrm{min}$} & \multicolumn{2}{|c|}{$1.0 \mathrm{~Gy} / \mathrm{min}^{\mathrm{a}}$} & \multicolumn{2}{|c|}{$0.38 \mathrm{~Gy} / \mathrm{min}^{\mathrm{b}}$} & \multirow{2}{*}{$\begin{array}{l}\text { Dose rate } \\
\left(\text { Gy } \mathrm{min}^{-1}\right)\end{array}$} & \multirow{2}{*}{ 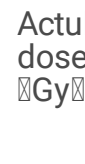 } \\
\hline & & & & $\begin{array}{l}\text { Estimates } \\
\bigotimes \text { Gy }\end{array}$ & $\begin{array}{l}\text { Errors } \\
\nabla \% \bigotimes\end{array}$ & $\begin{array}{l}\text { Estimates } \\
\bigotimes \text { Gy } \\
end{array}$ & $\begin{array}{l}\text { Errors } \\
\bigotimes \% \rrbracket\end{array}$ & $\begin{array}{l}\text { Estimates } \\
\text { Gy }\end{array}$ & $\begin{array}{l}\text { Errors } \\
\bigotimes \% \bigotimes\end{array}$ & & \\
\hline 2015 & A & 359 & 132 & 2.34 & -2.5 & 1.92 & -20.0 & 2.26 & -5.8 & 0.27 & 2.4 \\
\hline 2015 & B & 248 & 174 & 3.42 & 10.3 & 2.75 & -11.3 & 3.38 & 9.0 & 0.27 & 3.1 \\
\hline 2016 & A & 1142 & 1013 & 3.78 & 8.0 & 3.01 & -14.0 & 3.76 & 7.4 & 1.008 & 3.5 \\
\hline 2016 & B & 554 & 118 & 1.78 & 4.7 & 1.51 & -11.2 & 1.76 & 3.5 & 1.008 & 1.7 \\
\hline
\end{tabular}

Abbreviation: Dic, dicentric chromosome; $r$, centric rings

a $Y=8.0398 \times 10^{-2} D^{2}+3.4037 \times 10^{-2} D+7.3512 \times 10^{-3}$

Dose rate:1.0Gy/min囚National Standards GB/T28236-2011区.

b $Y=0.2297+6.8565 \times 10^{-2} D^{2}$

Dose rate: $0.38 \mathrm{~Gy} / \mathrm{min} \otimes \square$ Human radiation cytogenetics $\rrbracket$.

$Y=5.32 \times 10^{-2} \mathrm{D}+4.43 \times 10^{-2} D^{2} \bowtie 0.27 \mathrm{~Gy} \cdot \mathrm{min}^{-1} \otimes R^{2}=0.9999 \rrbracket$.

Table $3(2015,2016,2017)$ estimated results of biological dose of chromosome aberration in national assessment samples 


\begin{tabular}{|c|c|c|c|c|c|c|c|}
\hline \multicolumn{2}{|c|}{ sample number } & Cell Number & Dic+ r Number & Dic t r/Cell & Estimates $₫ \mathrm{~Gy} \rrbracket$ & 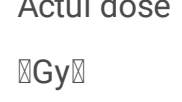 & Errors $₫ \% \bigotimes$ \\
\hline \multirow[t]{2}{*}{2015} & $32-A$ & 248 & 174 & 70.16 & 3.42 & 3.10 & +10.32 \\
\hline & $32-B$ & 359 & 132 & 36.77 & 2.34 & 2.40 & -2.5 \\
\hline \multirow[t]{2}{*}{2016} & $34-A$ & 1142 & 1013 & 88.70 & 3.90 & 3.50 & +14.29 \\
\hline & $36-B$ & 554 & 118 & 21.30 & 1.67 & 1.70 & -1.76 \\
\hline \multirow[t]{2}{*}{2017} & $39-1$ & 131 & 71 & 54.20 & 3.14 & 2.8 & 12.14 \\
\hline & $39-2$ & 841 & 227 & 27.00 & 1.94 & 1.7 & 14.12 \\
\hline
\end{tabular}

Abbreviation: Dic, dicentric chromosome; r, centric rings

Table 4. The Number of Cells and DICs Analyzed at Each Dose Point and Dose rate in the Fitted "Dose-Effect Curve by DIC Analysis."

\begin{tabular}{|lllllll|}
\hline $\begin{array}{l}\text { Dose rate } \\
\left(\text { Gy } \cdot \mathrm{min}^{-1}\right)\end{array}$ & $0.27 \mathrm{~Gy} \cdot \mathrm{min}^{-1}$ & $0.35 \mathrm{~Gy} \cdot \mathrm{min}^{-1}$ & $0.38 \mathrm{~Gy} \cdot \mathrm{min}^{-1}$ & $1.0 \mathrm{~Gy} \cdot \mathrm{min}^{-1}$ & $1.94 \mathrm{~Gy} \cdot \mathrm{min}^{-1}$ & $3.0 \mathrm{~Gy} \cdot \mathrm{min}^{-1}$ \\
\hline Absorbed Dose (Gy) & Dic t r/Cell & Dic t r/Cell & Dic t r/Cell & Dic t r/Cell & Dic t r/Cell & Dic t r/Cell $\mathbb{}$ \\
\hline 0.0 & 0.06 & 0.06 & 0.06 & 0.06 & 0.06 & 0.06 \\
\hline 0.10 & - & - & 0.32 & - & - & - \\
\hline 0.25 & 0.951 & - & 0.83 & - & - & - \\
\hline 0.50 & 3.420 & 2.07 & 1.90 & 2.80 & 3.85 & - \\
\hline 1 & 9.623 & 5.00 & 8.13 & 13.40 & 11.43 & 23.25 \\
\hline 2 & 29.677 & 21.00 & 23.33 & 43.80 & 33.25 & 73.50 \\
\hline 3 & 55.654 & 44.33 & 50.67 & 83.00 & 73.30 & 140.00 \\
\hline 4 & 91.173 & 77.67 & 99.00 & 137.00 & 120.30 & 221.00 \\
\hline 5 & 138.05 & 112.00 & 171.33 & 222.00 & 188.30 & 331.00 \\
\hline
\end{tabular}

Abbreviation: Dic, dicentric chromosome; $r$, centric rings

Table 5. The relationship between radiation dose and" k Value "or "b Value "were analyzed

\begin{tabular}{|lll|}
\hline Absorbed Dose (Gy) & k Value & $b$ Value \\
\hline 1 & 5.0740 & 5.00 \\
\hline 2 & 15.354 & 21.00 \\
\hline 3 & 29.299 & 44.33 \\
\hline 4 & 42.725 & 77.67 \\
\hline 5 & 62.054 & 112.00 \\
\hline
\end{tabular}

Table 6 The dose rate caused by the "dicentric+ring" increase in the share of the analysis (1) 


\begin{tabular}{|c|c|c|c|c|c|c|c|}
\hline Dose rate & Average & $1.0-0.35$ & $1.0-0.38$ & $1.94-0.35$ & $1.94-0.38$ & $3.0-0.35$ & $3.0-0.38$ \\
\hline$\left(G y \cdot \min ^{-1}\right)$ & (1.16Gy) & $0.65\left(\mathrm{~Gy} \cdot \mathrm{min}^{-1}\right)$ & $0.62\left(\mathrm{~Gy} \cdot \mathrm{min}^{-1}\right)$ & $1.59\left(\mathrm{~Gy} \cdot \mathrm{min}^{-1}\right)$ & $1.56\left(\mathrm{~Gy} \cdot \mathrm{min}^{-1}\right)$ & $2.65\left(\mathrm{~Gy} \cdot \mathrm{min}^{-1}\right)$ & $2.62\left(\mathrm{~Gy} \cdot \mathrm{min}^{-1}\right)$ \\
\hline $\begin{array}{l}\text { Absorbed } \\
\text { Dose (Gy) }\end{array}$ & $\begin{array}{l}\text { Dic+ } \\
\text { r/Cell }\end{array}$ & Dic+ r/Cell & Dic+ r/Cell & Dic+ r/Cell & Dic+ r/Cell & Dic+ r/Cell & Dic+ r/Cell \\
\hline 1 & 11.81 & 8.4 & 5.27 & 6.43 & 3.3 & 18.25 & 15.12 \\
\hline 2 & 37.43 & 22.8 & 20.47 & 12.25 & 9.92 & 52.50 & 50.17 \\
\hline 3 & 74.49 & 38.67 & 32.33 & 29.87 & 22.63 & 95.67 & 89.33 \\
\hline 4 & 124.36 & 59.33 & 38.00 & 42.63 & 21.30 & 143.33 & 122.00 \\
\hline 5 & 193.78 & 110 & 50.67 & 76.30 & 16.97 & 219.00 & 159.67 \\
\hline
\end{tabular}

Abbreviation: Dic, dicentric chromosome; $r$, centric rings

Table 7 The dose rate caused by the "dicentric+ring" increase in the share of the analysis (2)

\begin{tabular}{|lllll|}
\hline $\begin{array}{l}\text { Dose rate } \\
\left(\text { Gy } \cdot \mathrm{min}^{-1}\right)\end{array}$ & $\begin{array}{l}\text { Average } \\
(1.16 \mathrm{~Gy})\end{array}$ & $\begin{array}{l}0.03 \\
\left(\mathrm{~Gy} \cdot \mathrm{min}^{-1}\right)\end{array}$ & $\begin{array}{l}0.01 \\
\left(\mathrm{~Gy} \cdot \mathrm{min}^{-1}\right)\end{array}$ & \\
\hline Absorbed Dose (Gy) & Dic+ r/Cell & Dic $+\mathrm{r} /$ Cell & Dic $+\mathrm{r} /$ Cell & Dic+r/Cell \\
\hline 1 & 11.81 & 3.13 & 1.04 & 0.088 \\
\hline 2 & 37.43 & 2.33 & 0.78 & 0.021 \\
\hline 3 & 74.49 & 6.34 & 2.11 & 0.028 \\
\hline 4 & 124.36 & 21.33 & 7.11 & 0.057 \\
\hline 5 & 193.78 & 59.33 & 19.77 & 0.102 \\
\hline
\end{tabular}

Abbreviation: Dic, dicentric chromosome; $r$, centric rings

Figures 


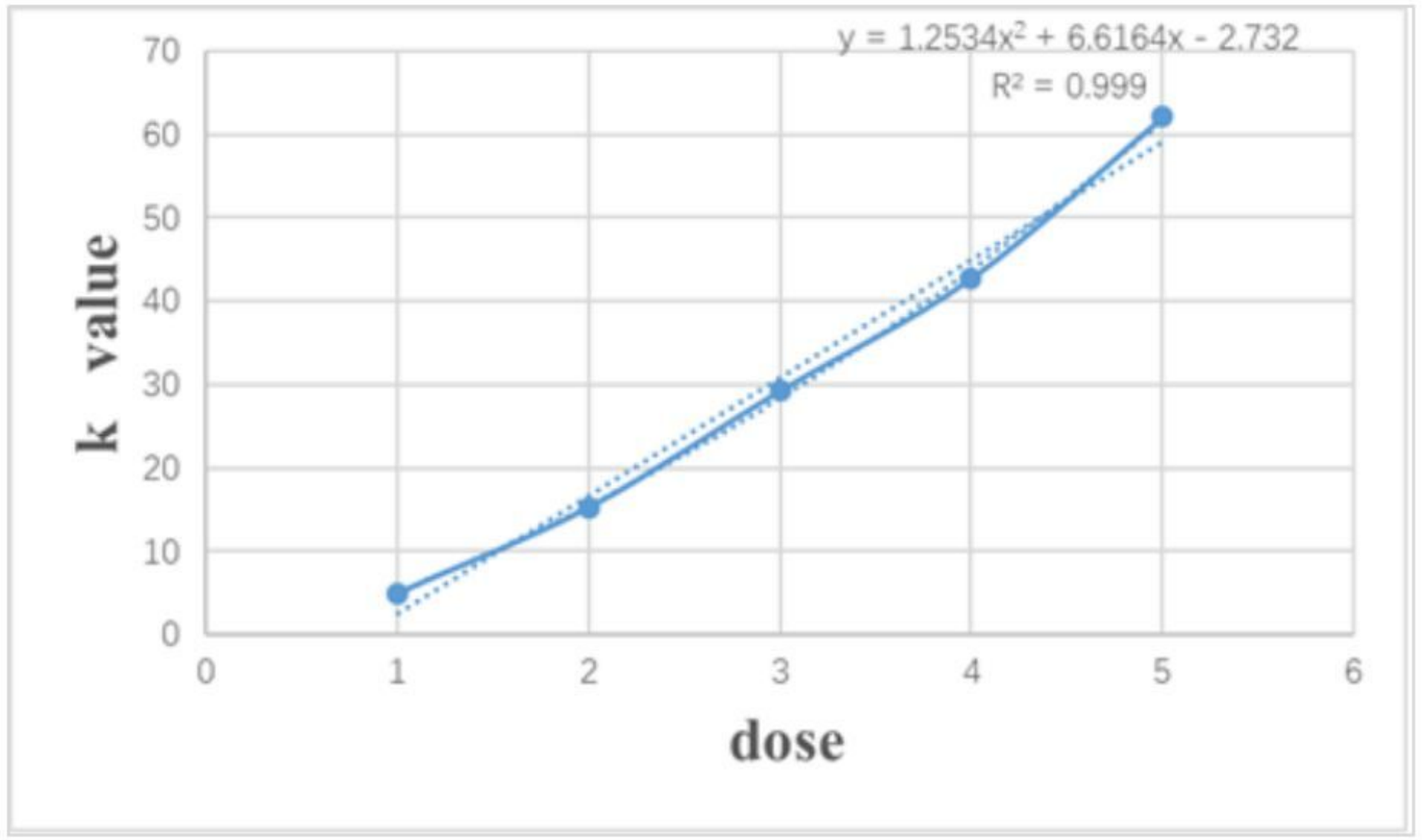

\section{Figure 1}

The relationship between radiation dose and $\mathrm{k}$ Value

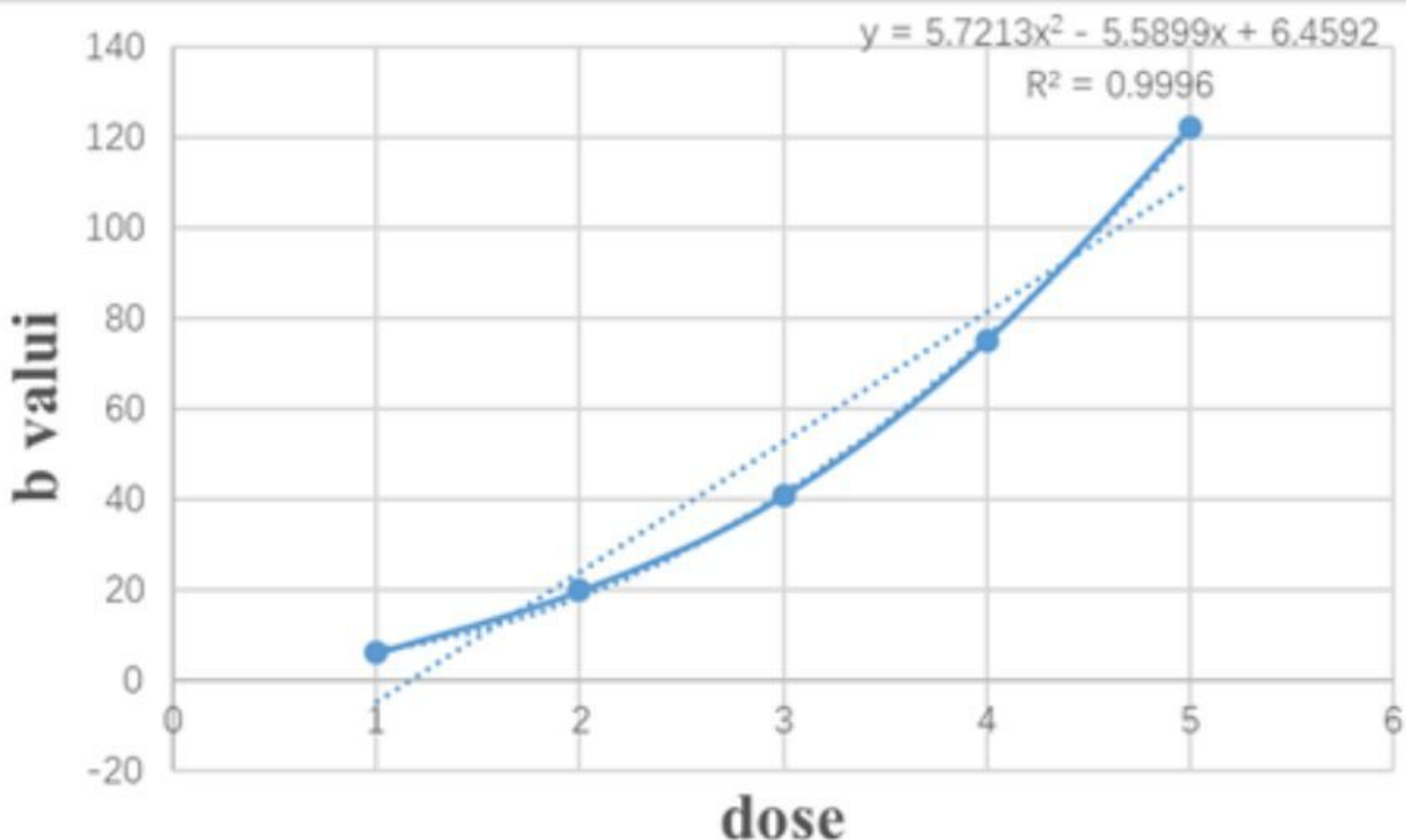




\section{Figure 2}

The relationship between radiation dose and $b$ Value

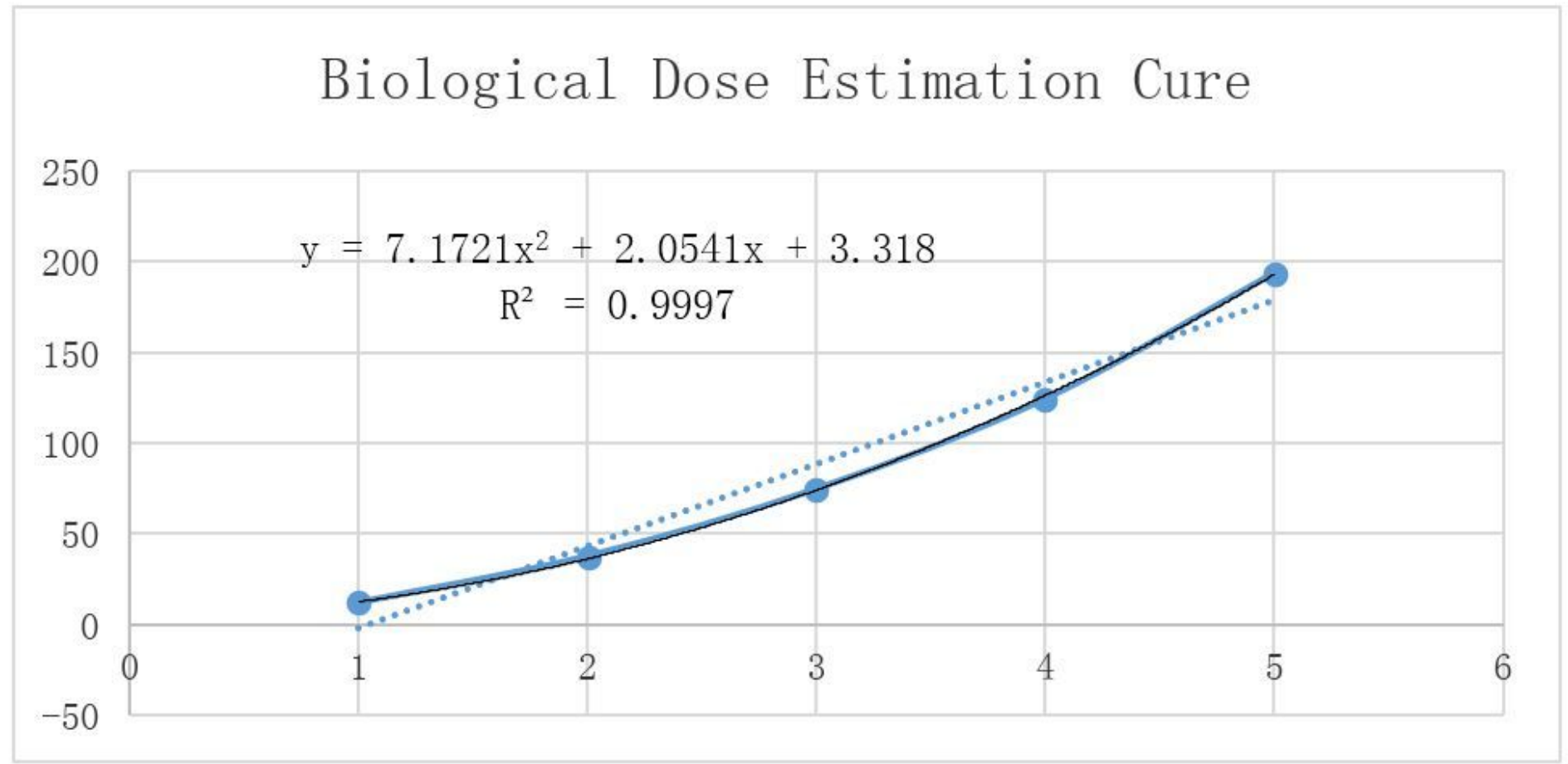

Figure 3

Biological dose estimation curve 